\title{
Acquired perforating dermatosis: clinicopathologic study of a 10-year period at a tertiary teaching hospital
}

\author{
Pedro Miguel Garrido ${ }^{1}$, MD Catarina Queirós ${ }^{1}$, MD, (D) João Borges-Costa ${ }^{1,2,3,4}$, PhD, \\ Luís Soares-Almeida ${ }^{1,2,3}, \mathrm{PhD}$ and Paulo Filipe ${ }^{1,2,3}$, PhD
}

\author{
${ }^{1}$ Dermatology Department, Centro \\ Hospitalar Universitário Lisboa Norte, EPE \\ (CHULN), Lisboa, Portugal, ${ }^{2}$ Unidade de \\ Investigação em Dermatologia, Instituto de \\ Medicina Molecular (IMM), Lisboa, \\ Portugal, ${ }^{3}$ Clínica Universitária de \\ Dermatologia, Faculdade de Medicina da \\ Universidade de Lisboa (FMUL), Lisboa, \\ Portugal, and ${ }^{4}$ Instituto de Higiene e \\ Medicina Tropical (IHMT), Universidade \\ Nova de Lisboa, Lisboa, Portugal

\section{Correspondence} \\ Pedro M. Garrido, MD \\ Centro Hospitalar Lisboa Norte EPE \\ Av. Prof. Egas Moniz \\ Lisboa 1649-035 \\ Portugal \\ E-mail: pedro.mi.garrido@gmail.com \\ Conflict of interest: None.
}

Funding source: None.

\begin{abstract}
Background Acquired perforating dermatosis (APD) comprises an uncommon group of skin disorders that develop in adulthood in association with systemic diseases. The aim of this study was to characterize clinicopathologic features and treatment outcomes in a series of patients diagnosed with APD.

Methods Retrospective study of all patients diagnosed with an APD over a 10-year period (2009-2018) at a tertiary teaching hospital in Lisbon, Portugal.

Results Fifty-seven patients with APD were identified. Thirty-five patients presented lesions in multiple anatomic areas (61.4\%), and the lower limbs were the most common location. Forty-six patients reported pruritus (80.7\%), which was classified as severe in 21 of them (36.8\%). An underlying systemic disease was identified in 53 patients (93.0\%). Diabetes mellitus (DM) and chronic kidney disease (CKD) were the most common associated systemic diseases, but psychiatric disorders, malignancies, and chronic infections were present in a significant number of patients. The combination of topical steroids with antihistamines was the most prescribed initial treatment, but only $37.8 \%$ of the patients had a complete response. Acitretin, systemic steroids, and phototherapy were the treatments associated with the best outcome.

Conclusion Acquired perforating dermatosis can be associated with many systemic disorders that have pruritus as a common factor. Chronic viral infections and an occult malignancy should be sought, particularly in the absence of DM and CKD. The management of APD is challenging and is best achieved with the control of the underlying systemic diseases.
\end{abstract}

doi: $10.1111 / \mathrm{ijd} .14760$

\section{Introduction}

Acquired perforating dermatosis (APD) comprises an uncommon group of skin disorders characterized by transepidermal elimination of dermal connective tissue components. ${ }^{1}$

Acquired perforating dermatosis usually develops in adulthood in association with diabetes mellitus (DM) and chronic kidney disease (CKD), but many other systemic disorders have been recently reported. ${ }^{2-6}$

Although there are a growing number of published case reports of APD, few series evaluate clinicopathologic features and management of patients with this disorder.

The aim of this study was to characterize a group of patients with the diagnosis of APD, focusing on associated systemic diseases and treatment outcomes.

\section{Materials and Methods}

A retrospective study was conducted on all patients

histopathologically diagnosed with an APD between January 1st,
2009, and December 31st, 2018, at Hospital de Santa Maria, a tertiary teaching hospital in Lisbon, Portugal. Data were obtained by reviewing dermatopathology registries and the clinical records.

A total of 57 patients were included in our study. The information recorded for each patient included gender, age, clinical features, distribution of skin lesions, clinical and histopathological diagnosis, associated systemic diseases, and treatment.

Treatment outcome was classified as complete response if there were no residual lesions or symptoms, partial response if there was an improvement but persistent lesions and/or pruritus, and no response if there was no improvement.

Renal function was measured by calculating estimated glomerular function rate (eGFR) using the abbreviated Modification of Diet in Renal Disease (MDRD) equation: GFR $=175 \times(\text { serum creatinine }[\mathrm{mg} / \mathrm{dL}])^{-1.154} \times($ age [years]) ${ }^{-0.203} \times 0.742$ (if female) $\times 1.21$ (if African American). ${ }^{7}$

Data were analyzed using the IBM SPSS Statistics ${ }^{\circledR}$ (Statistical Package for the Social Sciences, version 24, SPSS 
Inc, Chicago, IL, USA). Categorical variables were presented as frequencies and percentages, and continuous variables were presented as means and standard deviations or medians and interquartile ranges, for variables with skewed distribution.

\section{Results}

\section{Demographical and clinical characteristics}

Fifty-seven patients with APD were identified. Patient demographic and clinical characteristics are shown in Table 1.

Thirty-five patients presented lesions in multiple anatomic areas $(61.4 \%)$, and the lower limbs were the most common location.

Forty-six patients reported pruritus $(80.7 \%)$, which was classified as severe in 21 of them (36.8\%). No patient reported pain.

Diagnosis of APD was clinically suspected in 23 patients (40.4\%). The differential diagnoses mostly considered were prurigo nodularis, pityriasis lichenoid, calciphylaxis, and folliculitis.

\section{Associated systemic disorders}

An underlying systemic disease was identified in 53 patients (93.0\%). Twenty-four of these patients had more than one systemic disease $(42.1 \%)$. Associated systemic disorders are summarized in Table 2 and Fig. 1.

Twenty-seven patients had type 2 DM (47.4\%), and one had type $1 \mathrm{DM}$. Eighteen patients were taking only oral antidiabetic drugs (31.6\%), and 10 had insulin-treated DM (17.5\%). The mean glycated hemoglobin $(\mathrm{HbA1C})$ was $8.0 \%( \pm 1.5)$, with a range between 5.8 and $11.0 \%$. Nine patients presented an $\mathrm{HbA1C}$ higher than $8.0 \%$ (15.8\%).

Six patients with CKD (10.5\%) were on kidney replacement therapy, five on hemodialysis $(8.8 \%)$, and one on peritoneal dialysis. One patient was a kidney transplant recipient. The mean creatinine clearance was $28.9 \mathrm{~mL} / \mathrm{min} / \mathrm{m}^{2}( \pm 29.5)$, with a

Table 1 Patient demographic and clinical characteristics

\begin{tabular}{lc}
\hline $\begin{array}{l}\text { Patient demographic and clinical } \\
\text { characteristics }\end{array}$ & APD $(\boldsymbol{n}=\mathbf{5 7})$ \\
\hline Age at the diagnosis, mean (SD), years & $61.3( \pm 15.4)$ [range 37-96] \\
Male gender, No. (\%) & $29(50.9)$ \\
Anatomic distribution, No. (\%) & \\
Lower limbs & $40(70.2)$ \\
Upper limbs & $26(45.6)$ \\
Trunk & $25(43.9)$ \\
Head and neck & $4(7.0)$ \\
Clinical features, No. (\%) & \\
Excoriated and hyperkeratotic papules & $26(45.6)$ \\
Keratotic plugged, umbilicated papules & $18(31.6)$ \\
Crusted ulcers & $7(12.3)$ \\
\hline
\end{tabular}

APD, acquired perforating dermatosis; SD, standard deviation.
Table 2 Underlying systemic disorders

\begin{tabular}{lc}
\hline Underlying systemic disorders & No. (\%) \\
\hline DM & $28(49.1)$ \\
CKD & $16(28.1)$ \\
Psychiatric disorders & $12(21.1)$ \\
Malignancies & $9(15.8)$ \\
Infectious diseases & $8(14.0)$ \\
Hypothyroidism & $5(8.8)$ \\
Gastroenterological diseases (extrahepatic cholestasis, & $5(8.8)$ \\
$\quad$ celiac disease; ulcerative colitis, Wilson disease treated with & \\
Penicillamine) & \\
Rheumatological diseases (Sjögren syndrome, Still disease, & $5(8.8)$ \\
$\quad$ APS, CREST syndrome, psoriatic arthritis) & \\
Neurological diseases (Alzheimer disease, normal pressure & $4(7.0)$ \\
hydrocephalus, epilepsy, amyloidotic familiar & \\
polyneuropathy) & \\
\hline
\end{tabular}

APS, antiphospholipid syndrome; CKD, chronic kidney disease; CREST, calcinosis, Raynaud's phenomenon, esophageal dysmotility, sclerodactyly, and telangiectasia; DM, diabetes mellitus.

range between 0 and $67 \mathrm{~mL} / \mathrm{min} / \mathrm{m}^{2}$. Diabetic nephropathy was the most common etiology of CKD $(n=10 ; 17.5 \%)$.

The most frequent psychiatric diseases were depressive syndrome $(n=9 ; 15.8 \%)$ and anxiety disorder $(n=8 ; 14.0 \%)$. One patient had delusional parasitosis.

Among the nine patients with the diagnosis of a malignancy, four had a hematologic malignancy (two multiple myeloma, two non-Hodgkin lymphoma), three had solid organ neoplasms (lung, breast, and cervical cancer), and two had Kaposi sarcoma.

Chronic infectious diseases were present in eight patients, three of whom had human immunodeficiency virus (HIV) infection in acquired immunodeficiency syndrome (AIDS) stage (Fig. 2), two had hepatitis $C$ virus (HCV), and one hepatitis $B$ virus (HBV) infection. Two patients had chronic bacterial infections, of an orthopedic prothesis and a hepatic abscess.

A concomitant dermatological disorder was present in six patients $(10.5 \%)$. Psoriasis was the most frequent cutaneous disease $(n=4 ; 7.0 \%)$, followed by atopic eczema and bullous pemphigoid, each diagnosed in one patient.

Arterial hypertension and cardiovascular diseases were frequent comorbidities, present in 30 (52.6\%) and 23 (40.4\%) patients with APD, respectively. Chronic venous insufficiency, peripheral arterial disease, ischemic heart disease, stroke, and heart failure were the most commonly recorded cardiovascular diseases.

\section{Treatment and outcomes}

The treatment modalities and outcomes are shown in Table 3. The combination of topical steroids with antihistamines was the most prescribed initial treatment. In some patients, these drugs were combined with other treatments with a complete response: 

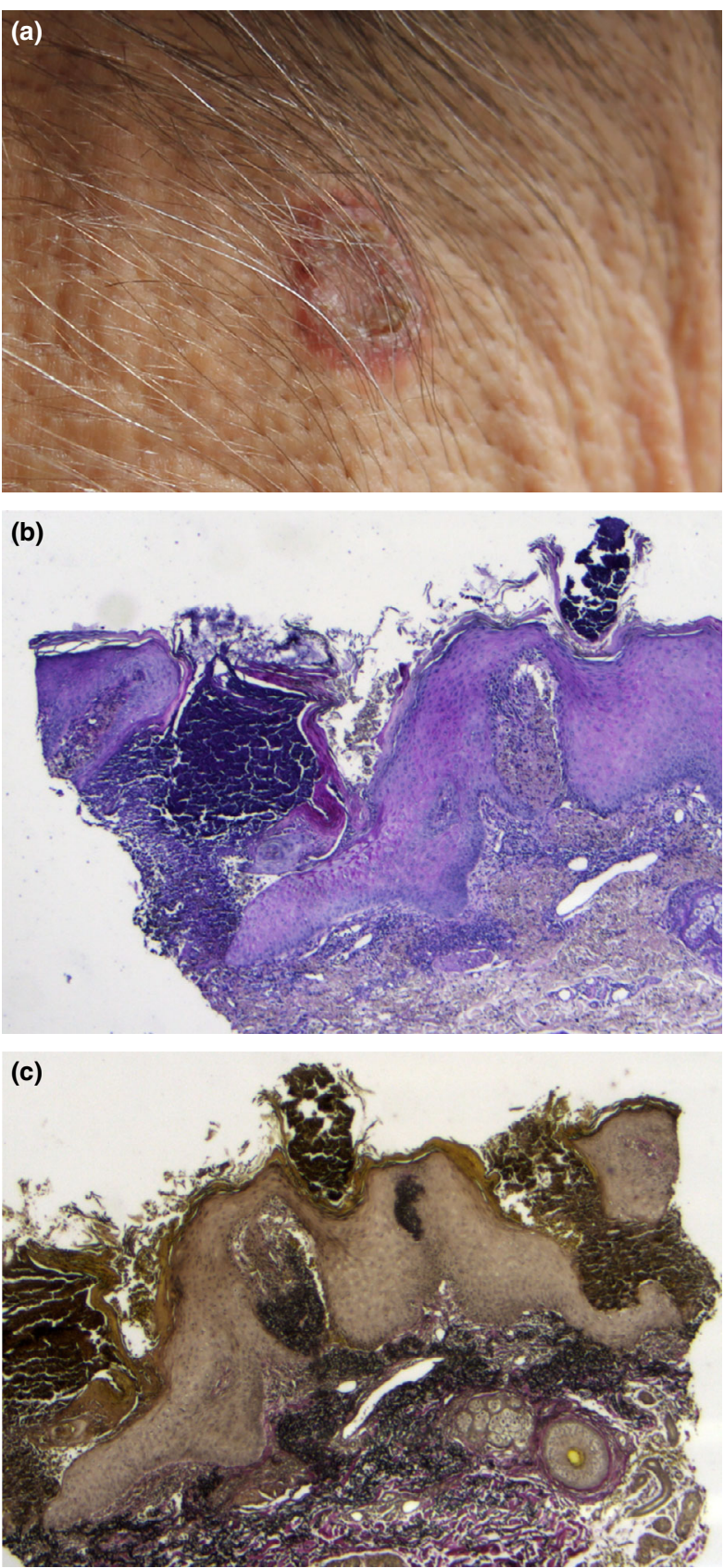

Figure 1 (a) Annular papular keratotic lesions on the posterior neck of a woman diagnosed with Wilson's disease for which she was taking D-penicillamine for the last 12 years. (b, c) Histological examination showing transepithelial elimination of degenerated elastic fibers with a "lumpy-bumpy" pattern [(Periodic acid-Schiff, $\times 100$ ); (Verhoeff-van Gieson, ×100), respectively]

systemic steroids in five patients with disseminated APD, bile duct dilatation in a patient with an iatrogenic stenosis, narrowband UVB (nbUVB) in a patient with concomitant eczema, topical calcipotriol in a patient with psoriasis, and switch of immunosuppression from tacrolimus to sirolimus in a kidney

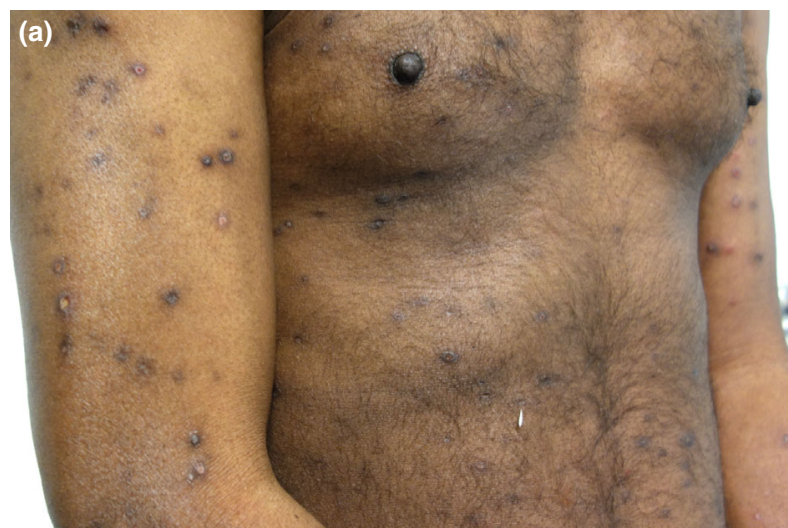

(b)

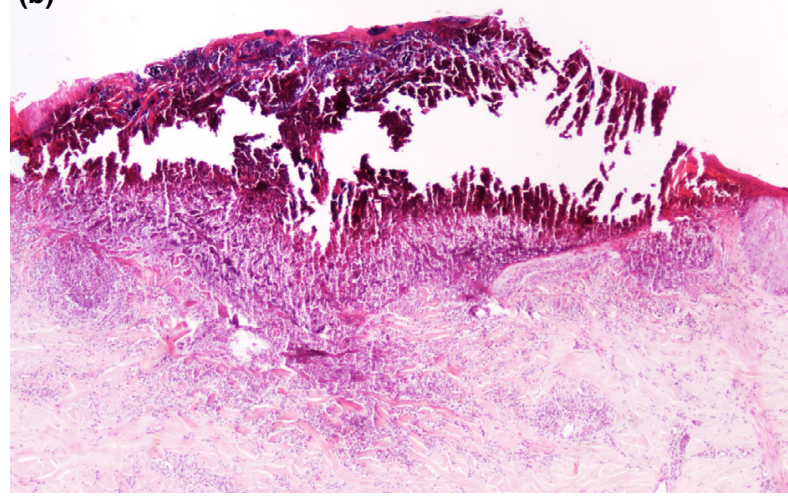

Figure 2 (a) Keratotic plugged, umbilicated papules on the trunk and upper limbs of a man with HIV infection in the stage of AIDS;

(b) Histological examination showing cup-shaped invagination of the epidermis, filled with basophilic degenerated collagen fibers, keratin, and crust $(\mathrm{H} \& \mathrm{E}, \times 100)$

transplant recipient. Intralesional steroids and doxycycline were used as first-line treatment in two patients, with a partial and no response, respectively.

After an incomplete response to initial treatment, second-line drugs included acitretin, systemic steroids, intralesional steroids, doxycycline, allopurinol, and psoralen plus UVA (PUVA) therapy. Acitretin, systemic steroids, and PUVA therapy were the treatments with best outcome.

After treatment, 31 patients had complete resolution of skin lesions (54.4\%), 13 presented partial improvement (22.8\%), and one presented no response. Five patients died within 6 months after the diagnosis of APD (8.8\%).

Patients presented a faster and more complete response for the resolution of the skin lesions than for the relief of pruritus.

\section{Discussion}

Since the first description of a case of APD in a diabetic woman in 1916 by Kyrle, four distinct entities have been identified and distinguished by the composition of the extruded material through the dermis: reactive perforating collagenosis, elastosis 


\begin{tabular}{lllll}
\hline Treatment outcome, No. & $\begin{array}{l}\text { Complete } \\
\text { response }\end{array}$ & $\begin{array}{l}\text { Partial } \\
\text { response }\end{array}$ & $\begin{array}{l}\text { No } \\
\text { response }\end{array}$ & Death \\
\hline $\begin{array}{l}\text { Topical steroids and antihistamines } \\
(n=37)\end{array}$ & $14(37.8 \%)$ & $13(35.1 \%)$ & $6(16.2 \%)$ & 4 \\
$(10.8 \%)$ & & & & \\
$\begin{array}{l}\text { Systemic steroids }(n=7) \\
(14.3 \%)\end{array}$ & $6(85.7 \%)$ & - & - & 1 \\
Intralesional steroids $(n=5)$ & $1(20.0 \%)$ & $4(80.0 \%)$ & - & - \\
Acitretin $(n=4)$ & $3(75.0 \%)$ & $1(25.0 \%)$ & - & - \\
Doxycycline $(n=2)$ & - & $1(50.0 \%)$ & $1(50.0 \%)$ & - \\
Allopurinol $(n=1)$ & - & - & $1(100.0 \%)$ & - \\
PUVA therapy $(n=1)$ & $1(100.0 \%)$ & - & - & - \\
nbUVB $(n=1)$ & $1(100.0 \%)$ & - & - & - \\
Topical calcipotriol $(n=1)$ & $1(100.0 \%)$ & - & - & - \\
\hline
\end{tabular}

Table 3 Treatment and outcomes

nbUVB, narrowband UVB; PUVA, Psoralen UVA.

perforans serpiginosa, Kyrle disease, and perforating folliculitis. ${ }^{1}$ However, overlapping features in pathologic examination in the same lesion can coexist, and some patients seem to present more than one subtype, making this classification unprecise. ${ }^{6,8,9}$ The term APD has been used to describe perforating dermatosis arising in adult patients with systemic diseases. ${ }^{6}$

The underlying systemic diseases most commonly reported are $\mathrm{DM}$ and $\mathrm{CKD}$, but an increasing number of disorders have been associated with APD. ${ }^{2-6}$ In this study, DM was the most common, and most patients were taking oral antidiabetic drugs. Similarly, previous series found a higher proportion of cases in non-insulin-dependent patients. ${ }^{3,9,10}$ In contrast, Morton et al. reported a higher number of insulin-dependent patients and suggested that these individuals were more likely to have sustained hyperglycemia and a longer duration of DM. ${ }^{11}$ The American Diabetes Association defines an $\mathrm{HbA1C}$ lower than $8.0 \%$ as the target for glycemic control in high-risk patients, such as those with $\mathrm{CKD} .{ }^{12}$ In the present study, mean $\mathrm{HbA1C}$ was $8.0 \%$, and $32.1 \%$ of diabetic patients had a $\mathrm{HbA} 1 \mathrm{C}$ higher than the defined target, emphasizing the possible role of poor glycemic control in the pathogenesis of APD.

Chronic kidney disease was the second most reported underlying systemic disease. The main cause of CKD was diabetic nephropathy, as in previous studies. ${ }^{3,6,11,13}$ Contrasting with other series, only $37.5 \%$ of the patients with CKD were receiving kidney replacement therapy. ${ }^{2,6,13}$ Although APD is scarcely reported in association with solid organ transplant, George et al. reported a prevalence of $2.7 \%$ in a series of kidney transplant recipients. ${ }^{14}$ We identified a case in a kidney transplant recipient without DM who was successfully treated with the combination of topical steroids, antihistamines, and the switch of immunosuppression from tacrolimus to sirolimus. This outcome contrasts with another report of APD that presented in a liver transplant recipient after starting therapy with sirolimus. ${ }^{15}$ The pathophysiology behind immunosuppressive drugs and the development of APD has yet to be established.
Psychiatric disorders not only can elicit pruritus and promote its persistence, but also chronic pruritus can decrease the quality of life and induce depressive and anxiety disorders. ${ }^{16}$ However, there are few reports of psychiatric diseases in patients diagnosed with APD. ${ }^{4,17}$ In the present series, psychiatric disorders affected 22 patients $(21.1 \%)$, and in five of them, there was no other underlying systemic disease.

The association of APD with malignancy has been reported both in patients with lymphoproliferative disorders, in particular Hodgkin disease, and in patients with solid organ neoplasms, such as prostate, hepatocellular, and breast carcinoma. ${ }^{18-25}$ Remarkably, APD was previously reported as the first presentation of an occult malignancy, and some authors suggest that this disorder might represent a paraneoplastic condition. ${ }^{22,24}$ In this series, an underlying malignancy was present in $15.8 \%$ of the patients. An occult neoplasm should be actively sought in the presence of suspicious symptoms, particularly in the absence of other underlying systemic diseases.

Chronic viral infections have also been associated with APD, namely HIV infection and chronic viral hepatitis. ${ }^{5,6,13,26-28}$ Moreover, protease inhibitors, including telaprevir and indinavir, have been implicated in its development as these drugs can elicit pruritus. ${ }^{26,29}$ Interestingly, in the present study, all patients with HIV infection presented in the setting of AIDS. Only one of these three patients was taking a protease inhibitor, and no other underlying systemic disease was identified, suggesting that the infection itself can induce the development of APD.

Although hypertension and cardiovascular diseases were frequent comorbidities in this study, we hypothesize that these disorders were not the dominant factor implicated in the development of APD, given its high prevalence on overall population and the fact that almost all of the patients presented other underlying systemic diseases, in particular DM and CKD. However, García-Malinis et al. proposed that vasculopathy underlying chronic venous insufficiency and hypertension might be involved in the pathogenesis of APD. ${ }^{2}$ 
The management of APD is challenging, and the evidencebased support for treatment comes from small case series and individual case reports. ${ }^{30}$ Treatment of underlying systemic diseases should always be considered and, sometimes, complete resolution of the dermatosis might be achieved. The association of topical steroids with oral antihistamines is usually the first modality of treatment. In contrast with previous series, only $37.8 \%$ of the patients had a complete response, emphasizing the need for other treatment options. ${ }^{2,3}$ Successful outcomes with tetracyclines, allopurinol, phototherapy, systemic retinoids, and systemic steroids have been reported..$^{2-4,30-32}$ In this series, few patients were treated with doxycycline and allopurinol, and both drugs were not an effective treatment alternative. Acitretin, systemic steroids, and phototherapy were the treatments associated with the best outcome and should be considered in the management of patients with disseminated lesions and severe pruritus, as well as in those who have a poor response to topical therapies.

The main limitations of this study rise from the fact that it has a retrospective design, with data obtained through the analysis of histopathology registries and medical records from a single center. Nevertheless, to the best of our knowledge, this is the largest series of APD.

\section{Conclusion}

Acquired perforating dermatosis is an uncommon group of skin disorders associated with a wide spectrum of systemic diseases that have pruritus as a common factor. Chronic viral infections and an occult malignancy should be sought, particularly in the absence of DM and CKD. The management of APD is challenging and is best achieved with control of the underlying systemic disorders.

\section{Acknowledgement}

We would like to acknowledge Ana Ortins-Pina and Miguel Duarte-Reis, Dermatology Department, Centro Hospitalar Universitário Lisboa Norte, for the courtesy of clinical pictures.

\section{References}

1 Patterson JW. The perforating disorders. J Am Acad Dermatol 1984; 10: 561-581.

2 García-Malinis AJ, del Valle Sánchez E, Sánchez-Salas MP, et al. Acquired perforating dermatosis: clinicopathological study of 31 cases, emphasizing pathogenesis and treatment. J Eur Acad Dermatol Venereol 2017; 31: 1757-1763.

$3 \mathrm{Kim}$ SW, Kim MS, Lee JH, et al. A clinicopathologic study of thirty cases of acquired perforating dermatosis in Korea. Ann Dermatol 2014; 26: 162-171.

4 Akoglu G, Emre S, Sungu N, et al. Clinicopathological features of 25 patients with acquired perforating dermatosis. Eur $J$ Dermatol 2013; 23: 864-871.

5 Satti MB, Aref AH, Raddadi AA, et al. Acquired reactive perforating collagenosis: a clinicopathologic study of 15 cases from Saudi Arabia. J Eur Acad Dermatol Venereol 2010; 24: 223-227.

6 Saray $Y$, Seçkin D, Bilezikçi B. Acquired perforating dermatosis: clinicopathological features in twenty-two cases. J Eur Acad Dermatol Venereol 2006; 20: 679-688.

7 Levey AS, Coresh J, Greene T, et al. Using standardized serum creatinine values in the modification of diet in renal disease study equation for estimating glomerular filtration rate. Ann Intern Med 2006; 145: 247-254.

8 Rapini RP, Herbert AA, Drucker CR. Acquired perforating dermatosis. Evidence for combined transepidermal elimination of both collagen and elastic fibers. Arch Dermatol 1989; 125: 1074-1078.

9 Faver IR, Daoud MS, Su WP. Acquired reactive perforating collagenosis. Report of six cases and review of the literature. $J$ Am Acad Dermatol 1994; 30: 575-580.

10 Hong SB, Park JH, Ihm CG, et al. Acquired perforating dermatosis in patients with chronic renal failure and diabetes mellitus. J Korean Med Sci 2004; 19: 283-288.

11 Morton CA, Henderson IS, Jones MC, et al. Acquired perforating dermatosis in a British dialysis population. $\mathrm{Br} \mathrm{J}$ Dermatol 1996; 135: 671-677.

12 American Diabetes Association. Glycemic targets: standards of medical care in diabetes-2018. Diabetes Care 2018; 41(Suppl 1): S55-S64

13 González-Lara L, Gómez-Bernal S, Vázquez-López F, et al. Acquired perforating dermatosis: a report of 8 cases. Actas Dermosifiliogr Dermosifiliogr 2014; 105: e39-e43.

14 George L, John GT, Jacob CK, et al. Skin lesions in renal transplant recipients: a single center analysis. Indian J Dermatol Venereol Leprol 2009; 75: 255-261.

15 Lübbe J, Sorg O, Malé PJ, et al. Sirolimus-induced inflammatory papules with acquired reactive perforating collagenosis. Dermatology 2008; 216: 239-242.

16 Schneider G, Driesch G, Heuft G, et al. Psychosomatic cofactors and psychiatric comorbidity in patients with chronic itch. Clin Exp Dermatol 2006; 31: 762-767.

17 Tampa M, Sârbu MI, Matei C, et al. Kyrle's disease in a patient with delusions of parasitosis. Rom J Intern Med 2016; 54: 66-69.

18 Rivera-Rodríguez A, Prieto-Torres L, Felipo-Berlanga F, et al. Acquired reactive perforating collagenosis associated with Hodgkin disease. Clin Exp Dermatol 2017; 42: 934-936.

19 Eigentler TK, Metzler G, Brossart P, et al. Acquired perforating collagenosis in Hodgkin's disease. J Am Acad Dermatol 2005; 52: 922.

20 Quinlan C, Boggs J, Finan M, et al. A case of paraneoplastic elastosis perforans serpiginosa associated with ovarian malignancy. Int J Dermatol 2018; 57: 470-472.

21 Singh EN, Kumar S, Agarwal US, et al. Acquired reactive perforating collagenosis associated with mediastinal synovia sarcoma. Clin Exp Dermatol 2019; 44: 325-327.

22 Yazdi S, Saadat P, Young S, et al. Acquired reactive perforating collagenosis associated with papillary thyroid carcinoma: a paraneoplastic phenomenon? Clin Exp Dermato/2010; 35: 152-155.

$23 \mathrm{Kim} \mathrm{RH}$, Kwa M, Adams S, et al. Giant acquired reactive perforating collagenosis in a patient with diabetes mellitus and metastatic breast carcinoma. JAAD Case Rep 2016; 2: 22-24.

24 Kurban M, Uthman I, Kibbi AG, et al. Acquired perforating dermatosis heralding metastatic renal cell carcinoma to the liver. Int J Dermatol 2008; 47: 1038-1040.

25 Lee YS, Vijayasingam S, Tan YO, et al. Acquired perforating dermatosis associated with recurrent hepatocellular carcinoma. Int J Dermatol 1996; 35: 743-745.

26 Pernet C, Pageaux GP, Guillot B, et al. Telaprevir-induced acquired perforating dermatosis. JAMA Dermato/2014; 150: 1371-1372. 
27 Rubio FA, Herranz P, Robayna G, et al. Perforating folliculitis: report of a case in an HIV-infected man. J Am Acad Dermatol 1999; 40(2 Pt 2): 300-302.

28 Nogueira Farias GM, Pinto JR, Melo JC, et al. Kyrle's disease associated with HIV infection, diabetes, and chronic kidney disease. Indian J Pathol Microbiol 2018; 61: 414-417.

29 Calista D, Morri M. Acquired reactive perforating collagenosis induced by indinavir in 2 patients with HIV disease. Eur $J$ Dermatol 2008; 18: 84-85.
30 Lukács J, Schliemann S, Elsner P. Treatment of acquired reactive perforating dermatosis - a systematic review. J Dtsch Dermatol Ges 2018; 16: 825-842.

31 Karpouzis A, Giatromanolaki A, Sivridis E, et al. Acquired reactive perforating collagenosis: current status. J Dermatol 2010; 37: 585-592.

32 Hoque SR, Ameen M, Holden CA. Acquired reactive perforating collagenosis: four patients with a giant variant treated with allopurinol. Br J Dermatol 2006; 154: 759-762. 